\title{
Human frailties
}

\section{The First Human: The Race to Discover Our Earliest Ancestors \\ by Ann Gibbons}

Doubleday: 2006. 336 pp. \$26

\section{Ian Tattersall}

Once upon a time it was the 'missing link'. Then it was the earliest member of our genus Homo. Now the target of palaeoanthropology is the 'first human', our most ancient fossil ancestor not shared with the great apes. Such shifts in fashion demonstrate that, like any other branch of science, palaeoanthropology changes with the times. Some things, however, have remained comfortingly constant. One of these is the regular public laundering of palaeoanthropology's dirty linen, which has long been a mainstay of the popular science literature, combining as it does the delights of gossip and voyeurism with a fascinating subject matter. And as a few years have passed since Jon Kalb's entertaining and instructive Adventures in the Bone Trade (Copernicus, 2000; reviewed in Nature 410, 517-518; 2001), perhaps it is indeed time to trawl again through the rich and swirling palaeoanthropological pond, as Ann Gibbons does in her absorbing new book, The First Human.

Little more than a decade ago, the human story seemed to begin essentially with Australopithecus afarensis, the early hominid species from eastern Africa epitomized by Lucy, the most famous hominid fossil of them all. With representatives from a variety of sites spanning the period between about 4 million and 3 million years ago, the small-brained and diminutive $A$. afarensis was an upright biped when on the ground (albeit in a manner somewhat different from ours), but retained enough ancestral features to be viewed today as a bipedal ape.

The key feature that had set humankind on its unique evolutionary path had been energetically debated for a century, but the combination of characteristics displayed by Lucy and her kind seemed to settle the argument in favour of two-legged terrestrial walking. This conclusion was bolstered by palaeoenvironmental data, which indicated that, over the past several million years, Africa has been subject to a drying trend, leading to forest being replaced by woodland and grasslands. In some areas at least, this forced hominoid populations to the ground, as their ancestral forest habitat disappeared.

Over the past dozen years, a slew of even more ancient hominid finds has been claimed from various parts of Africa. First there was Australopithecus (later Ardipithecus) ramidus, published in Nature in 1994. This fragmentary form is 4.4 million years old, and was later joined by bits and pieces of a claimed relative up to 5.8 million years old old. In 1995 there followed Australopithecus anamensis, from
Kenyan sites up to about 4.2 million years old. In the 'really ancient' category (molecular estimates of the divergence of the human and ape lineages run at around 6 million to 8 million years ago), Orrorin tugenensis was described from 6-million-year-old deposits in Kenya in 2001, followed a year later by Sahelanthropus tchadensis, from slightly older sediments in Chad.

Each of these poorly known species derives its putative hominid status essentially from the claim that it was an erect biped. But upright locomotion is inferred from very indirect evidence in every case except $A$. anamensis, and these fossils make up an oddly assorted group. If they are all indeed descended from a unique common ancestor, then from the very beginning our precursors were experimenting wildly with different ways to be hominid. On the other hand, even if all these forms really were bipedal, perhaps, faced with similar environmental pressures, several hominoid lineages sharing a tendency to upright arboreal postures might independently have adopted this approach to a partly terrestrial life. Amid all this uncertainty, though, one thing is plain: it is in the interests of the palaeoanthropologists concerned that 'their' fossils be hominid rather than merely representatives of nowextinct lineages of apes.

In such a situation it is only to be expected that there should be keen competition among the various groups of scientists involved in the quest for the first human. And so it is that, after a historical overview, Gibbons' book is largely devoted to recounting the sometimes savage rivalries between these factions over the past decade and a half. Virtually all the protagonists are smart, dedicated and hardworking scientists, but some are also worthy of Machiavelli's The

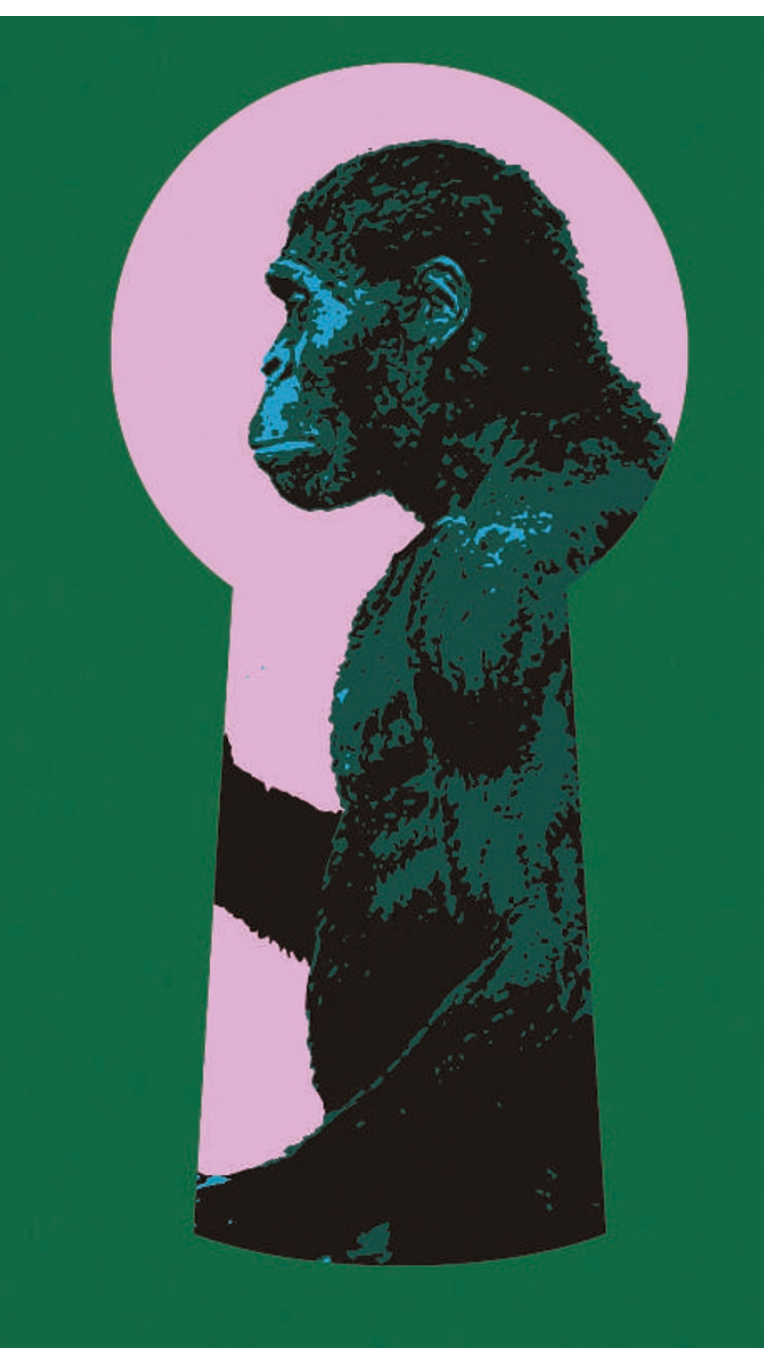

Prince. If their energies were devoted simply to demonstrating the hominid status of their fossils by any means available, the worst that could result would be a certain measure of confusion. Which is what we have: after years of argument, we still have no idea what the first human ought to look like. But to complicate matters further, palaeoanthropology is too often seen as a sort of zero-sum game, with the result that published specimens are often vigorously defended from the eyes of rival scientists, making it impossible to test the describers' published assertions. What other branch of science keeps its primary data secret?

The ideal enquiry into this murky world might thus usefully ask some indiscreet questions. But even though it would be unfair to call The First Human hagiography, Gibbons' tone remains generally deferential. This is hardly surprising because, as a correspondent for Science magazine, Gibbons still has to talk regularly to her subjects. But it does limit her freedom to explain the many bizarre episodes she recounts, or indeed the intellectual framework of the underlying quest. So although this readable book will bring you up to speed on 